\title{
Impact of Norepinephrine and Fluid on Cerebral Oxygenation in Experimental Hemorrhagic Shock
}

\author{
PATRICK MEYBOHM, JOCHEN RENNER, ANDREAS BOENING, EROL CAVUS, JAN-THORSTEN GRÄSNER, \\ MATTHIAS GRÜNEWALD, JENS SCHOLZ, AND BERTHOLD BEIN
}

\begin{abstract}
Department of Anesthesiology and Intensive Care Medicine [P.M., J.R., E.C., J.-T.G., M.G., J.S., B.B.], Department of Cardiac and Vascular Surgery [A.B.], Pediatric Anesthesia Research Unit [P.M., J.R., B.B.]; University Hospital Schleswig-Holstein, Campus Kiel, 24105 Kiel, Germany
\end{abstract}

\begin{abstract}
Few data exist regarding resuscitation of hypovolemic shock in infants, and alternative strategies such as vasopressor therapy merit further evaluation. However, the effects of norepinephrine on cerebral perfusion and oxygenation during hemorrhagic shock in the pediatric population are still unclear. Eight anesthetized piglets were subjected to hypotension by blood withdrawal of $25 \mathrm{~mL} / \mathrm{kg}$. Norepinephrine was titrated to achieve baseline mean arterial blood pressure (MAP), and cerebral oxygenation was determined by brain tissue $\mathrm{Po}_{2}\left(\mathrm{P}_{\mathrm{ti}} \mathrm{O}_{2}\right)$ and near-infrared spectroscopy-derived tissue oxygen index (TOI). Then, norepinephrine was stopped, MAP was allowed to decrease again below $30 \mathrm{~mm} \mathrm{Hg}$, and shed blood was retransfused. During hemorrhage, TOI dropped from $69 \pm 3$ to $59 \pm$ $3 \%$, and $\mathrm{P}_{\mathrm{ti}} \mathrm{O}_{2}$ from $29 \pm 6$ to $13 \pm 1 \mathrm{~mm} \mathrm{Hg}$ (mean $\pm \mathrm{SEM} ; p<$ 0.001). Following norepinephrine, cerebral perfusion pressure (CPP) could be restored immediately, whereas TOI and $\mathrm{P}_{\mathrm{ti}} \mathrm{O}_{2}$ did not increase significantly. In contrast, following retransfusion, TOI and $\mathrm{P}_{\mathrm{ti}} \mathrm{O}_{2}$ increased to $68 \pm 3 \%$ and $27 \pm 7 \mathrm{~mm} \mathrm{Hg}$ reaching baseline values, respectively. In conclusion, while norepinephrine increased CPP immediately, cerebral oxygenation as reflected by TOI and $\mathrm{P}_{\mathrm{ti}} \mathrm{O}_{2}$ could not be improved by norepinephrine, but only by retransfusion.

(Pediatr Res 62: 440-444, 2007)
\end{abstract}

$\mathrm{H}^{5}$ ypovolemia is the most common cause of circulatory failure in children (1). When inadequate tissue perfusion is not recognized and treated rapidly, critical tissue hypoxia may develop, leading to multiorgan failure and global cerebral ischemia followed by impaired brain function (2). With respect to hypovolemic and hemorrhagic shock, few clinical and experimental data exist in infants (3). In adults, there is growing evidence that conventionally aggressive fluid resuscitation does not increase the chance of survival in hemorrhagic shock (4). Accordingly, alternative strategies such as vasopressor therapy merit further evaluation. Administration of the widely used norepinephrine (NE) has been advocated to control hypotension, even in the acute phase of hemorrhage (5). Preliminary experimental data have suggested that early administration of NE may improve cerebral perfusion and oxygenation, at least in a model of brain-injury (6). However, the effects of NE on systemic hemodynamics

Received March 21, 2007; accepted May 23, 2007.

Correspondence: Patrick Meybohm, M.D., University Hospital Schleswig-Holstein Campus Kiel, Department of Anesthesiology and Intensive Care Medicine, Schwanenweg 21, 24105 Kiel, Germany; e-mail: meybohm@anaesthesie.uni-kiel.de

Funding was restricted to institutional and departmental sources of the University Hospital Schleswig-Holstein. and cerebral perfusion and oxygenation in a pediatric model of hemorrhagic shock are still unclear.

NIRS is a relatively new technique with the capacity to detect changes in cerebral hemodynamics and oxygenation continuously and noninvasively at the bedside (7). In addition, impaired cerebral oxygenation has been found to correlate closely to experimental hypotension-induced alterations in cerebral blood flow (CBF) (8). Thus, we undertook this study to determine in a pediatric model of hemorrhagic shock 1) whether changes in cerebral perfusion and oxygenation accompanying hemorrhage could be detected by NIRS, and 2) whether the use of NE would improve cerebral perfusion and oxygenation.

\section{MATERIALS AND METHODS}

This is an experimental study on eight healthy piglets, ranging from 2 to 3 wk of age of either gender, weighing 6-10 kg. Anesthesia was used in all surgical interventions. The project was approved by the Animal Investigation Committee of the University Schleswig-Holstein, Campus Kiel, Germany, and the animals were managed in accordance with institutional guidelines and the Utstein-style guidelines. All animals received human care in compliance with the Guide for the Care and Use of Laboratory Animals published by the National Institutes of Health (National Institutes of Health Publication No. 88.23, revised 1996).

Animal preparation. The animals were fasted overnight, but had free access to water. The piglets were premedicated with azaperone (neuroleptic agent; 8 $\mathrm{mg} / \mathrm{kg}$ i.m. $)$ and atropine $(0.05 \mathrm{mg} / \mathrm{kg}$ i.m. $) 1 \mathrm{~h}$ before surgery, and anesthesia was induced with a bolus dose of propofol (1-2 $\mathrm{mg} / \mathrm{kg}$ i.v. $)$ and sufentanil $(0.3$ $\mu \mathrm{g} / \mathrm{kg}$ i.v.). After endotracheal intubation during spontaneous respiration, the pigs were ventilated with a volume-controlled ventilator (Siemens SV 900C, Berlin, Germany) with $40 \%$ oxygen at 25 breaths/min, and with a tidal volume of $10 \mathrm{~mL} / \mathrm{kg}$. Anesthesia was maintained with a continuous infusion of propofol $(8 \mathrm{mg} / \mathrm{kg} / \mathrm{h})$ and sufentanil $(0.3 \mu \mathrm{g} / \mathrm{kg} / \mathrm{h}) ;$ muscle relaxation was provided by continuous infusion of pancuronium $(0.2 \mathrm{mg} / \mathrm{kg} / \mathrm{h})$. Ringer's solution $(10 \mathrm{~mL} / \mathrm{kg} / \mathrm{h})$ was administered continuously throughout the preparation phase to replace fluid loss during instrumentation. A standard lead II ECG was used to monitor cardiac rhythm; depth of anesthesia was judged according to blood pressure and heart rate during the preparation phase. In our experience, the piglets do not respond to painful or auditory stimuli under this anesthetic regimen when the paralyzing agent is withheld, and the loading dose of propofol subsides. If clinical assessment suggested a decreasing level of anesthesia, additional sufentanil and propofol was injected.

A 5-F pulmonary artery catheter (PAC; Edwards Swan Ganz Combo EDV Thermodilution Catheter, Baxter Laboratories, Irvine, CA) was inserted via a
Abbreviations: CBF, cerebral blood flow; CO, cardiac output; CPP, cerebral perfusion pressure; $\mathbf{F V}_{\text {mean }}$, mean blood flow velocity; MAP, mean arterial blood pressure; NIRS, near-infrared spectroscopy; $\mathbf{P}_{\mathbf{t i}} \mathbf{O}_{\mathbf{2}}$, brain tissue partial pressure of oxygen; $\mathbf{S o}_{2}$, peripheral oxygen saturation; $\mathbf{S V R}$, systemic vascular resistance; TOI, tissue oxygen index 
6-F introducer in the right internal jugular vein, advanced under continuous pressure recording into wedge position and then connected to a cardiac output (CO) computer system (Vigilance Monitor, Baxter Edwards Critical Care, Irvine, $\mathrm{CA}$ ). $\mathrm{CO}$ was determined by bolus pulmonary artery thermodilution using $5 \mathrm{~mL}$ ice-cold saline injected in the proximal port of the PAC three times randomly assigned to the respiratory cycle. A 4-F saline-filled catheter was advanced into the right femoral artery for monitoring mean arterial blood pressure (MAP), heart rate (HR), and for blood withdrawal. Intravascular catheters were attached to pressure transducers (Smiths Medical, Kirchseeon, Germany) that were aligned at the level of the right atrium. Ventilation was monitored using an inspired/expired gas analyzer that measured oxygen and end-tidal carbon dioxide $\left(\mathrm{ETCO}_{2}\right.$; suction rate, $200 \mathrm{~mL} / \mathrm{min}$; M-PRESTN; Datex-Ohmeda Inc., Helsinki, Finland). Oxygen saturation $\left(\mathrm{SO}_{2}\right)$ was monitored by a continuous pulse oximeter placed on the ear (M-CAiOV; DatexOhmeda Inc.). For brain parameter access, a multiluminal probe introducer (Licox IM3.STV, GMS, Kiel, Germany) was inserted via a 5.3-mm skull burr hole $(10 \mathrm{~mm}$ paramedian and $10 \mathrm{~mm}$ cranial of the coronal suture) for measurement of the brain tissue $\mathrm{Po}_{2}\left(\mathrm{P}_{\mathrm{ti}} \mathrm{O}_{2}\right)$ corrected for brain temperature (Licox CMP, GMS, Kiel, Germany), and intracranial pressure (ICP; Ventrix, Integra NeuroSciences, Plainsboro, NJ). Calibration at room air (to determine the sensitivity-drift) and in oxygen free solution (to determine the zero-drift) was performed after removal of the $\mathrm{P}_{\mathrm{ti}} \mathrm{O}_{2}$-catheters. Cerebral perfusion pressure (CPP) was defined as MAP minus ICP $(\mathrm{CPP}=\mathrm{MAP}-\mathrm{ICP})$. All catheters were flushed with isotonic saline containing $5 \mathrm{IU} / \mathrm{mL}$ heparin at a rate of $3 \mathrm{~mL} / \mathrm{h}$ to prevent obstruction during the preparation phase. Body temperature was monitored by a rectal temperature probe and maintained between 37 and $38^{\circ} \mathrm{C}$ with a heating blanket. Arterial blood gases for analyzing $\mathrm{pH}, \mathrm{Hb}, \mathrm{Po}_{2}$, and $\mathrm{PCO}_{2}$ were measured with a blood-gas analyzer (ABL System 615; Radiometer Medical Inc.; Copenhagen, Denmark).

NIRS. The technique of NIRS has been described in detail elsewhere (9). Briefly, the NIRO 300 (Hamamatsu Photonics, Herrsching, Germany) is a noninvasive monitor allowing measurement of tissue oxygen index (TOI) that represents the ratio of oxygenated to total tissue $\mathrm{Hb}$. Four wavelengths of light $(775,810,850$, and $910 \mathrm{~nm}$, respectively) are delivered by four pulsed laser diodes, and scattered light is detected by three closely placed photodiodes. The optodes of the NIRS were placed on the skin overlying the right cerebral hemisphere just on a line $1 \mathrm{~cm}$ lateral to the midsagittal plane and anterior to the coronal suture to avoid signal irritation by the sagittal sinus. For optimal spatial resolution, the interoptode distance was set to $3 \mathrm{~cm}$. The path length was adjusted according to the manufacturer's instructions for measurements on an intact human skull. The optodes were covered with opaque material and secured to the head with adhesive tape.

Transcranial Doppler ultrasound. Cerebral blood flow velocity was determined by transcranial Doppler ultrasound (DWL, Sipplingen, Germany) using the temporal bone window. With a 2-MHz pulsed Doppler probe, the left middle cerebral artery was insonated at a depth of $20-28 \mathrm{~mm}$, and mean blood flow velocity $\left(\mathrm{FV}_{\text {mean }}\right)$ was recorded. The transducer was kept fixed in place by an elastic headband to ensure a stable position of vessel insonation.

Experimental protocol. After instrumentation for cerebral and hemodynamic variables, and a 120-min equilibration phase, baseline measurements including all variables described previously were obtained. Then propofol infusion was adjusted to $4 \mathrm{mg} / \mathrm{kg} / \mathrm{h}$ and infusion of Ringer's solution was stopped before induction of shock. Blood was withdrawn with a total of 25 $\mathrm{mL} / \mathrm{kg}$ of body weight by stepwise volumes of $5 \mathrm{~mL} / \mathrm{kg}$. The procedure lasted approximately $20 \mathrm{~min}$ or less and was terminated if MAP decreased below 30 $\mathrm{mm} \mathrm{Hg}$. A second set of hemodynamic data and cerebral oxygenation measurements was made after blood withdrawal. Then, NE was titrated to achieve a MAP $\pm 10 \%$ of baseline. Approximately $15 \mathrm{~min}$ after hemorrhage, a third set of data were obtained during NE administration. Then, NE administration was stopped, and MAP was allowed to decrease again below $30 \mathrm{~mm} \mathrm{Hg}$ during the following $20 \mathrm{~min}$ to rule out any residual drug effects. Afterward, shed blood was retransfused, and a final set of hemodynamic and cerebral data were obtained after retransfusion. After finishing the experimental protocol, the animals were euthanized with an overdose of propofol, sufentanil, and potassium chloride. All piglets were then subjected to necropsy to check for correct positioning of the catheters, and damage to internal organs.

Statistical analysis. Statistics were performed using commercially available statistics software (GraphPad Prism version 4.03 for Windows, GraphPad Software, San Diego, CA, and SPSS for Windows, version 11.5, SPSS, Inc., Chicago, IL). A Kolmogorov-Smirnov test was used to test for Gaussian distribution. One-way repeated measures ANOVA followed by Bonferroni correction for multiple comparisons was used to determine statistical significance of cerebral and hemodynamic variables, cerebral oxygenation, and blood gases at different time points. All variables are expressed as mean \pm SEM. The relationship between variables was analyzed according to the method described by Bland and Altman (10). First, we calculated a linear regression for each animal with TOI being the outcome variable and $\mathrm{P}_{\mathrm{ti}} \mathrm{O}_{2}$ the predictor variable followed by analysis of covariance (ANCOVA). This type of analysis was also applied to analyze the relationship of TOI and $\mathrm{FV}_{\text {mean }}$ and $\mathrm{CO}$ and $\mathrm{FV}_{\text {mean }}$, respectively. Statistical significance was considered at a two-sided $p$ value of $\leq 0.05$.

\section{RESULTS}

Hemodynamic data and blood gases at the different experimental stages are presented in Table 1. Following hemorrhage, both systemic parameters, such as MAP, systemic vascular resistance (SVR), CO and CVP, and cerebral hemodynamics, such as CPP and $\mathrm{FV}_{\text {mean }}$, decreased significantly ( $p<0.001$; Fig. 1$)$, whereas HR increased significantly $(p<0.001)$. Furthermore, hemorrhage resulted in a significant decrease of cerebral oxygenation compared with baseline, as TOI dropped from $69 \pm 3$ to $59 \pm 3 \%$, and $\mathrm{P}_{\mathrm{ti}} \mathrm{O}_{2}$ from $29 \pm 6$ to $13 \pm 1 \mathrm{~mm} \mathrm{Hg}$ ( $p<0.001$; Fig. 2).

Approximately $15 \mathrm{~min}$ after hemorrhage, NE administration resulted in an increase of SVR from $522 \pm 85$ to $1194 \pm$ 192 dyne*sec/cm ${ }^{5}$, and subsequently an increase of MAP and $\mathrm{CPP}$ to baseline values, as well as $\mathrm{FV}_{\text {mean }}$ reaching $80 \%$ of

Table 1. Hemodynamic data and blood gases

\begin{tabular}{lcccc}
\hline & Baseline & Hemorrhage & NE & Retransfusion \\
\hline $\mathrm{HR}$, beats/min & $140 \pm 12$ & $184 \pm 14^{*}$ & $195 \pm 13$ & $158 \pm 11^{* * \neq}$ \\
$\mathrm{MAP}, \mathrm{mm} \mathrm{Hg}$ & $67 \pm 5$ & $31 \pm 2^{*}$ & $68 \pm 5 \dagger$ & $69 \pm 6 \dagger$ \\
$\mathrm{CVP}, \mathrm{mm} \mathrm{Hg}$ & $4 \pm 1$ & $2 \pm 1^{*}$ & $2 \pm 1^{*}$ & $5 \pm 1 \dagger \neq$ \\
$\mathrm{CO}, \mathrm{L} / \mathrm{min}$ & $1.6 \pm 0.2$ & $0.9 \pm 0.1^{*}$ & $1.3 \pm 0.1^{* *}$ & $1.5 \pm 0.2 \dagger \neq$ \\
$\mathrm{SVR}, \mathrm{dyne} \mathrm{sec}^{5} \mathrm{~cm}^{5}$ & $778 \pm 155$ & $522 \pm 85^{*}$ & $1194 \pm 192 \dagger$ & $724 \pm 69 \ddagger$ \\
$\mathrm{ICP}, \mathrm{mm} \mathrm{Hg}$ & $14 \pm 1$ & $11 \pm 2^{*}$ & $12 \pm 2$ & $16 \pm 2 \dagger \neq$ \\
$\mathrm{So}_{2}, \%$ & $99 \pm 1$ & $99 \pm 1$ & $99 \pm 1$ & $99 \pm 1$ \\
$\mathrm{ETCO}_{2}, \mathrm{~mm} \mathrm{Hg}$ & $41 \pm 2$ & $38 \pm 3$ & $40 \pm 3$ & $42 \pm 2$ \\
$\mathrm{Po}_{2}, \mathrm{~mm} \mathrm{Hg}$ & $180 \pm 20$ & $179 \pm 33$ & $186 \pm 18$ & $192 \pm 14$ \\
$\mathrm{PCO}_{2}, \mathrm{~mm} \mathrm{Hg}$ & $44 \pm 4$ & $47 \pm 3$ & $46 \pm 4$ & $43 \pm 5$ \\
$\mathrm{Hemoglobin}_{\mathrm{g}} \mathrm{g} / \mathrm{dL}$ & $7.9 \pm 0.6$ & $8.1 \pm 0.4$ & $7.8 \pm 0.7$ & $7.7 \pm 0.6$ \\
$\mathrm{pH}$ & $7.33 \pm 0.03$ & $7.30 \pm 0.05$ & $7.30 \pm 0.04$ & $7.32 \pm 0.03$ \\
\hline
\end{tabular}

Values are mean $\pm \operatorname{SEM}(n=8) . * p<0.001 v s$ baseline; $* * p<0.05 v s$ hemorrhage; $\dagger p<0.001 v s$ hemorrhage; $\ddagger p<0.05$ vs NE. HR, heart rate; $\mathrm{CVP}$, central venous pressure; ICP, intracranial pressure; $\mathrm{ETCO}_{2}$, end-tidal partial pressure of carbon dioxide; $\mathrm{PO}_{2}$, partial pressure of oxygen; $\mathrm{PCO}_{2}$, partial pressure of carbon dioxide.

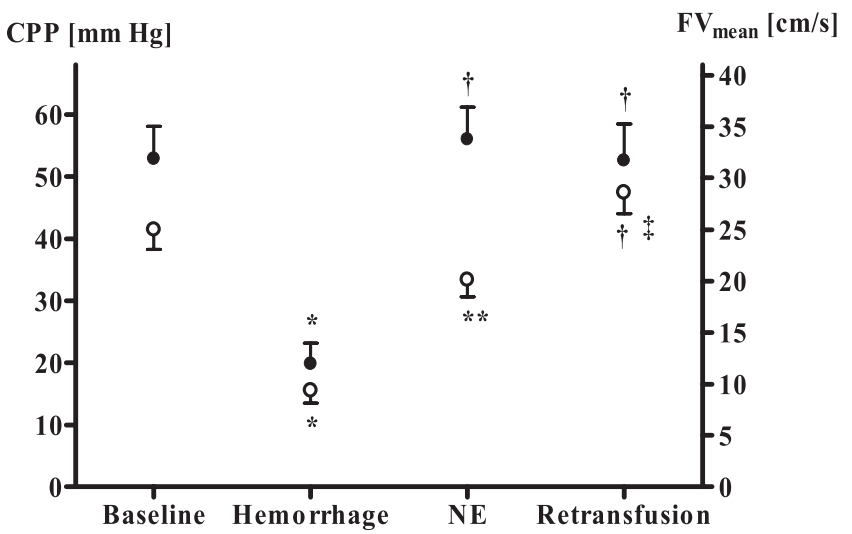

Figure 1. $\mathrm{CPP}(\mathrm{mm} \mathrm{Hg}, \bullet)$ and $\mathrm{FV}_{\text {mean }}(\mathrm{cm} / \mathrm{s}, \bigcirc)$ at the different experimental stages $(n=8) .{ }^{*} p<0.001 v s$ baseline; $* * p<0.01 v s$ hemorrhage; $\dagger p<0.001$ vs hemorrhage; $\ddagger p<0.05$ vs NE. NE indicates norepinephrine. The values are given as mean \pm SEM. 


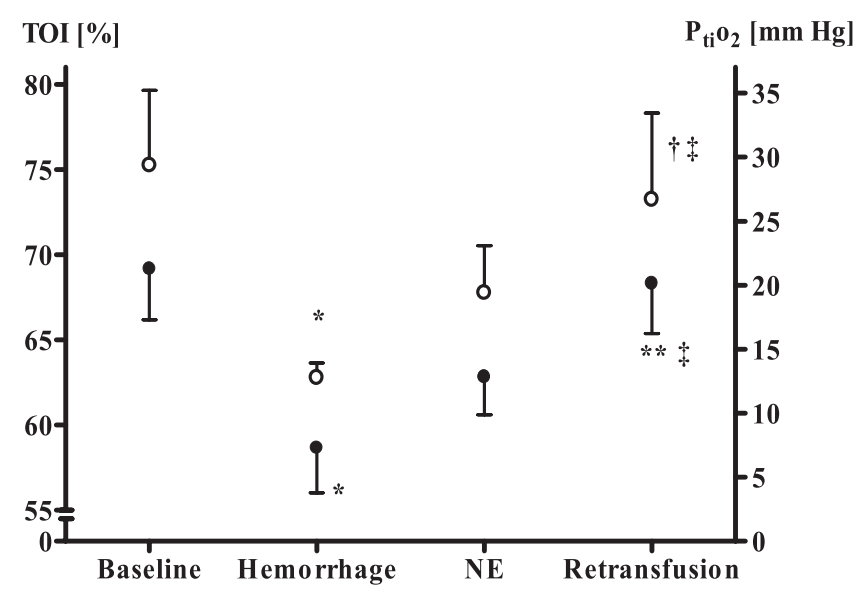

Figure 2. TOI $(\%, \bullet)$ and $\mathrm{P}_{\mathrm{ti}} \mathrm{O}_{2}(\mathrm{~mm} \mathrm{Hg}, \mathrm{O})$ at the different experimental stages $(n=8) . * p<0.001 v s$ baseline; $* * p<0.001 v s$ hemorrhage; $\dagger p<$ 0.05 vs hemorrhage; $\ddagger p<0.05$ vs NE. NE indicates norepinephrine. The values are given as mean \pm SEM.

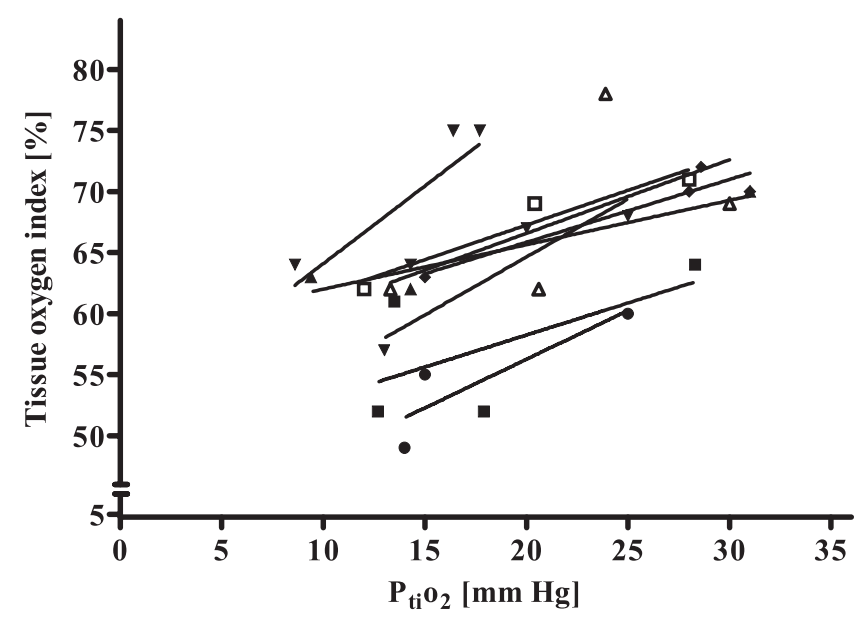

Figure 3. Correlation between tissue oxygen index and $\mathrm{P}_{\mathrm{ti}} \mathrm{O}_{2}$ in eight individual animals. Linear regression line for each animal $(r=0.70, p<0.01)$. $n=24$ measurements in eight animals.

baseline value. With respect to cerebral oxygenation, TOI and $\mathrm{P}_{\mathrm{ti}} \mathrm{O}_{2}$ did not increase significantly $(63 \pm 2 \%$ and $19 \pm$ $2 \mathrm{~mm} \mathrm{Hg}$ ).

After NE administration was stopped, MAP decreased again close to values during hemorrhage during the following $20 \pm 3 \mathrm{~min}$. Then, retransfusion of shed blood resulted in an increase of MAP, CO, CVP, SVR, CPP, and $\mathrm{FV}_{\text {mean }}$ reaching baseline values (Table 1, Fig. 1). TOI and $\mathrm{P}_{\mathrm{ti}} \mathrm{O}_{2}$ increased significantly to $68 \pm 3 \%$ and $27 \pm 7 \mathrm{~mm} \mathrm{Hg}$, respectively, compared with both hemorrhage and NE (Fig. $2 ; p<0.05$ ).

TOI was significantly correlated with $\mathrm{P}_{\mathrm{ti}} \mathrm{O}_{2}(r=0.70$; Fig. 3; $p<0.01)$ and $\mathrm{FV}_{\text {mean }}(r=0.70$; Fig. 4; $p<0.01)$. $\mathrm{CO}$ was significantly correlated with $\mathrm{FV}_{\text {mean }}(r=0.52$; Fig. 5; $p<0.05)$. Blood gases, $\mathrm{Hb}, \mathrm{So}_{2}$, and $\mathrm{ETCO}_{2}$ did not change significantly during the experiment (Table 1). Overall, resuscitation was successful in eight out of eight animals. Necropsy revealed correct position of all catheters, no additional damage to internal organs, and no micro hemorrhages at the $\mathrm{P}_{\mathrm{ti}} \mathrm{O}_{2}$ probe site.

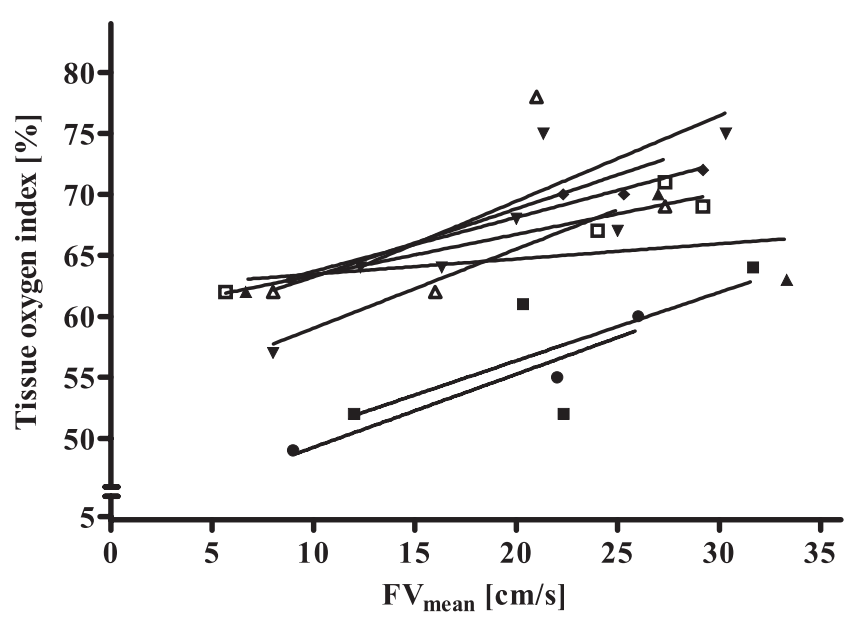

Figure 4. Correlation between $\mathrm{TOI}$ and $\mathrm{FV}_{\text {mean }}$ in eight individual animals. Linear regression line for each animal. $(r=0.70, p<0.01) . n=25$ measurements in eight animals.

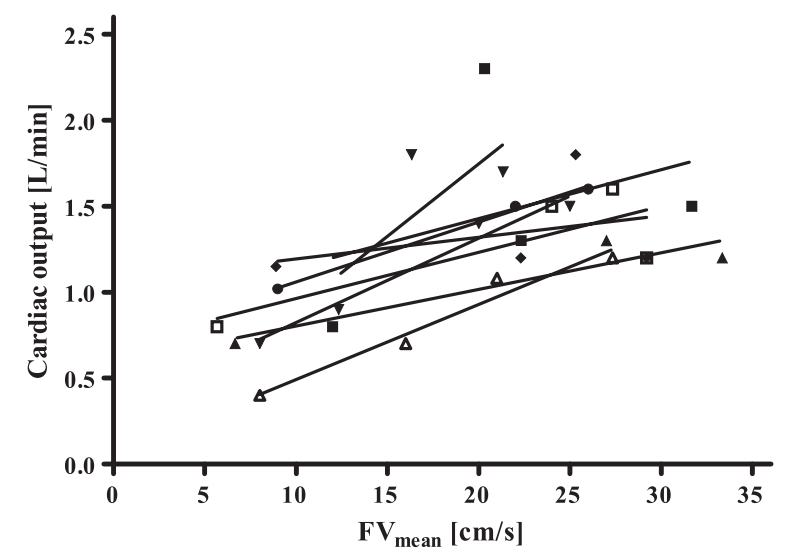

Figure 5. Correlation between $\mathrm{CO}$ and $\mathrm{FV}_{\text {mean }}$ in eight individual animals. Linear regression line for each animal. $(r=0.52, p<0.05) . n=25$ measurements in eight animals.

\section{DISCUSSION}

Main findings of our experimental study are as follows: 1) Although systemic oxygenation as reflected by arterial $\mathrm{Po}_{2}$ and peripheral $\mathrm{So}_{2}$ remained on a sufficient level throughout the experiment, cerebral oxygenation assessed both regionally by NIRS-derived TOI and locally by $\mathrm{P}_{\mathrm{ti}} \mathrm{O}_{2}$ decreased profoundly during hemorrhagic shock in our pediatric model. 2) $\mathrm{NE}$ administration increased MAP and CPP to baseline values, but NE did not improve significantly cerebral oxygenation, thus refuting the primary endpoint hypothesis. Hence, cerebral oxygenation as reflected by both TOI and $\mathrm{P}_{\mathrm{ti}} \mathrm{O}_{2}$ was only restored by retransfusion, whereas MAP and CPP were comparable to NE. 3) TOI was significantly correlated with $\mathrm{P}_{\mathrm{ti}} \mathrm{O}_{2}$ and $\mathrm{FV}_{\text {mean }}$.

Tissue hypoxia is a key factor in the pathophysiology of circulatory shock. Therefore, we have focused in this study on cerebral oxygenation, measured regionally by NIRS (TOI) and locally by the Licox system $\left(\mathrm{P}_{\mathrm{ti}} \mathrm{O}_{2}\right)$, two parameters of cerebral oxygenation that differ fundamentally in the type of data provided. It has been shown previously that during normal circulatory conditions, brain tissue oxygenation is maintained relatively constant independently of cerebral perfusion pres- 
sure within the autoregulatory range of brain circulation (11), comparable to the well-known regulation of CBF. In contrast, during hypotension, a pressure-passive $\mathrm{CBF}$ and cerebral ischemia have been found as assessed by NIRS $(8,12)$ and the Licox system (13). Our data confirm these results, as TOI and $\mathrm{P}_{\mathrm{ti}} \mathrm{O}_{2}$ decreased profoundly during hemorrhagic shock. Moreover, $\mathrm{P}_{\mathrm{ti}} \mathrm{O}_{2}$ values below $15 \mathrm{~mm} \mathrm{Hg}$ have been suggested to reflect a critical threshold for survival, at least in severe head injured patients (14). We have demonstrated previously that during impaired autoregulation immediately following hemorrhage, cerebral perfusion and CPP are closely correlated (12). Since in the present study CPP was markedly below the autoregulatory threshold in the vast majority of animals, we suggest a pressure dependent cerebral perfusion that in turn led to the observed decrease of both regional and local cerebral oxygenation. In contrast, systemic oxygenation represented by $\mathrm{PO}_{2}$ remained on a sufficient level and uncoupled from $\mathrm{P}_{\mathrm{ti}} \mathrm{O}_{2}$ during hemorrhage.

Although fluid resuscitation of hemorrhagic shock and surgical control of hemorrhage are the strategies of choice (15), sometimes aggressive fluid resuscitation and out-of-hospital surgery is not immediately available or not sufficient to maintain blood pressure in all preclinical situations. Therefore, the primary goal of treatment for hemorrhagic shock until final therapy is the restoration of tissue perfusion and oxygenation, to shorten the time interval of global and regional ischemia, and to minimize brain injury. The purpose of the present study was to reproduce this crucial clinical situation in pediatric emergency care. NE is a potent vasoactive agent with alphaand beta-adrenergic properties that is widely used for the treatment of hypotension secondary to vasodilatation in hemorrhagic or septic shock (16), and that has no effect on cerebrovascular hemodynamics during intact circulation (17). The rationale for NE therapy during hemorrhagic shock is rooted in the fact that NE has been claimed to shift venous blood from unstressed to stressed vascular bed (18). Therefore, NE administration may support activation of the endogenous sympatho-adrenergic system in shifting blood volume to the central compartment, and thereby, preserving blood flow to the heart and brain. Although in our pediatric model of hemorrhagic shock NE resulted in an increase of SVR, and subsequently an increase of MAP and CPP close to baseline values, this did not translate into improved cerebral perfusion and oxygenation reflected by $\mathrm{FV}_{\text {mean }}$ and cerebral oxygenation variables. In contrast, cerebral perfusion assessed by TCD and cerebral oxygenation as reflected by both TOI and $\mathrm{P}_{\mathrm{ti}} \mathrm{O}_{2}$ were only restored by retransfusion, and were subsequently significantly improved compared with hemorrhage and NE administration. This is probably due to the pathophysiological mechanism that restoration of intravascular volume is a prerequisite of normal cardiac output after hemorrhagic shock. Alternatively, fluid resuscitation according to the international recommendations about resuscitation of hemorrhagic shock (15) might equally restore intravascular volume, but may also result in decreased $\mathrm{Hb}$ levels (19), that profoundly interact with cerebral oxygenation data (20). Therefore, we evaluated the effects of NE on cerebral oxygenation compared with blood transfusion, but further investigations should focus on different fluid therapy strategies regarding cerebral oxygenation. In addition, raising CPP in head injured patients has been shown previously to not necessarily result in increased oxygen availability and $\mathrm{P}_{\mathrm{ti}} \mathrm{O}_{2}(21,22)$.

TOI and $\mathrm{P}_{\mathrm{ti}_{\mathrm{O}}} \mathrm{O}_{2}$ reflect adequate cerebral perfusion more reliably than CPP. If cerebral arterial oxygen saturation and cerebral metabolic rate of oxygen are constant, changes of $\mathrm{CBF}$ will produce equal change in cerebral venous oxygen saturation. Because TOI mainly reflects oxygenation changes in the venous compartment of cerebral blood volume (23), it is expected to vary with $\mathrm{CBF}$ and $\mathrm{FV}_{\text {mean }}$, and less with $\mathrm{CPP}$ during periods of constant cerebral arterial oxygen saturation and oxygen consumption.

Further, from our data, the issue of relationship between TOI measured regionally by NIRS and $\mathrm{P}_{\mathrm{ti}} \mathrm{O}_{2}$ measured locally by the Licox system may be addressed. Both parameters of cerebral oxygenation differ fundamentally in the type of data provided, but were correlated significantly. This has also been found in head injured patients, where changes of $\mathrm{P}_{\mathrm{ti}} \mathrm{O}_{2}$ were closely reflected by NIRS-derived variables (24). In addition, the interaction between cerebral oxygen saturation and $\mathrm{P}_{\mathrm{ti}} \mathrm{O}_{2}$ has been described by a sigmoid-shaped oxygen-Hb dissociation curve (25). The noninvasive NIRS technology may therefore be suitable to accurately monitor cerebral oxygenation at the bedside, at least in infants where the issue of extracranial signal contamination is not that important.

Several limitations to this study should be noted. First, measurement of $\mathrm{P}_{\mathrm{ti}} \mathrm{O}_{2}$ with a probe placed in the cerebral cortex is a local method and may therefore underestimate global ischemia due to heterogeneity of the brain. However, not stereotactically, the spatial variation of $\mathrm{P}_{\mathrm{ti}} \mathrm{O}_{2}$ probe placement in different animals was kept within a narrow limit. Second, the path length of NIRS in the porcine head is unknown and thus we used the published data derived from human experiments (26). Although there may be a difference between species, this does not interfere with the results of our study, since it was aimed at investigating changes over time rather than presenting absolute values. Further, NIRS technology may be influenced by extracerebral contamination. Third, since we were unable to measure $\mathrm{CBF}$ using radioactive microspheres due to limitations posed by government regulations, we cannot comment on effects of drugs given throughout the study on CBF. Doppler ultrasound is limited due to the fact that it is not direct measurement of CBF (27). However, in the present investigation $\mathrm{FV}_{\text {mean }}$ was significantly correlated to both $\mathrm{CO}$ and TOI, a relationship that is physiologically plausible. Moreover, although animals were free of NE at least $20 \mathrm{~min}$ before transfusion, we cannot completely rule out a "long-term" effect of NE perfusion on brain tissue oxygenation. Due to the small sample size of piglets caused by the long preparation procedure, we used a design of successive exposure to two different treatments instead of comparing each treatment in a separate group of animals. Finally, we used $\mathrm{NE}$ as a vasopressor; therefore, we are unable to report whether different vasopressors would have yielded other results. Future investigations should focus on the relationship between histopathological changes and cerebral oxygenation parameters, and vasopressors that act via nonadrenergic path- 
ways such as arginine vasopressin that may influence differently CPP and cerebral oxygenation.

In conclusion, in spite of well-developed autoregulatory mechanisms, CPP as well as TOI and $\mathrm{P}_{\mathrm{ti}} \mathrm{O}_{2}$ decreased significantly during hemorrhagic shock. Following NE administration, MAP and CPP could be restored immediately, but cerebral perfusion and oxygenation as reflected by TOI and $\mathrm{P}_{\mathrm{ti}} \mathrm{O}_{2}$ could not be improved by $\mathrm{NE}$ alone, but only by retransfusion. In this respect, normal MAP values following resuscitation with $\mathrm{NE}$ alone of hemorrhage-induced hypotension do not rule out compromised cerebral oxygenation, and therefore, should not be regarded as safe during pronounced fluid deficiency.

Acknowledgments. The authors thank Volkmar HaenselBringmann, R.N., for excellent technical assistance and logistic support, and Juergen Hedderich, Ph.D., for statistical advice.

\section{REFERENCES}

1. Carcillo JA, Tasker RC 2006 Fluid resuscitation of hypovolemic shock: acute medicine's great triumph for children. Intensive Care Med 32:958-961

2. Anwar M, Agarwal R, Rashduni D, Weiss HR 1996 Effects of hemorrhagic hypotension on cerebral blood flow and perfused capillaries in newborn pigs. Can J Physiol Pharmacol 74:157-162

3. Boluyt N, Bollen CW, Bos AP, Kok JH, Offringa M 2006 Fluid resuscitation in neonatal and pediatric hypovolemic shock: a Dutch Pediatric Society evidence-based clinical practice guideline. Intensive Care Med 32:995-1003

4. Capone AC, Safar P, Stezoski W, Tisherman S, Peitzman AB 1995 Improved outcome with fluid restriction in treatment of uncontrolled hemorrhagic shock. J Am Coll Surg 180:49-56

5. Flint LM, Cryer HM, Simpson CJ, Harris PD 1984 Microcirculatory norepinephrine constrictor response in hemorrhagic shock. Surgery 96:240-247

6. Kroppenstedt SN, Thomale UW, Griebenow M, Sakowitz OW, Schaser KD, Mayr PS, Unterberg AW, Stover JF 2003 Effects of early and late intravenous norepinephrine infusion on cerebral perfusion, microcirculation, brain-tissue oxygenation, and edema formation in brain-injured rats. Crit Care Med 31:2211-2221

7. Soul JS, du Plessis AJ 1999 New technologies in pediatric neurology. Near-infrared spectroscopy. Semin Pediatr Neurol 6:101-110

8. Tsuji M, du Plessis A, Taylor G, Crocker R, Volpe JJ 1998 Near infrared spectroscopy detects cerebral ischemia during hypotension in piglets. Pediatr Res 44:591595

9. Bein B, Cavus E, Stadlbauer KH, Tonner PH, Steinfath M, Scholz J, Dorges V 2006 Monitoring of cerebral oxygenation with near infrared spectroscopy and tissue oxygen partial pressure during cardiopulmonary resuscitation in pigs. Eur J Anaesthesiol 23:501-509
10. Bland JM, Altman DG 1995 Calculating correlation coefficients with repeated observations: part 1-Correlation within subjects. BMJ 310:446

11. Hemphill JC 3rd, Knudson MM, Derugin N, Morabito D, Manley GT 2001 Carbon dioxide reactivity and pressure autoregulation of brain tissue oxygen. Neurosurgery 48:377-383

12. Bein B, Meybohm P, Cavus E, Tonner PH, Steinfath M, Scholz J, Doerges V 2006 A comparison of transcranial Doppler with near infrared spectroscopy and indocyanine green during hemorrhagic shock: a prospective experimental study. Crit Care 10:R18

13. Jaeger M, Schuhmann MU, Soehle M, Meixensberger J 2006 Continuous assessment of cerebrovascular autoregulation after traumatic brain injury using brain tissue oxygen pressure reactivity. Crit Care Med 34:1783-1788

14. Valadka AB, Gopinath SP, Contant CF, Uzura M, Robertson CS 1998 Relationship of brain tissue PO2 to outcome after severe head injury. Crit Care Med 26:15761581

15. Spahn DR, Cerny V, Coats TJ, Duranteau J, Fernandez-Mondejar E, Gordini G, Stahel PF, Hunt BJ, Komadina R, Neugebauer E, Ozier Y, Riddez L, Schultz A, Vincent JL, Rossaint R Task Force for Advanced Bleeding Care in Trauma 2007 Management of bleeding following major trauma: a European guideline. Crit Care 11:R17

16. Mullner M, Urbanek B, Havel C, Losert H, Waechter F, Gamper G 2004 Vasopressors for shock. Cochrane Database Syst Rev:CD003709

17. Strebel SP, Kindler C, Bissonnette B, Tschaler G, Deanovic D 1998 The impact of systemic vasoconstrictors on the cerebral circulation of anesthetized patients. Anesthesiology 89:67-72

18. Nouira S, Elatrous S, Dimassi S, Besbes L, Boukef R, Mohamed B, Abroug F 2005 Effects of norepinephrine on static and dynamic preload indicators in experimental hemorrhagic shock. Crit Care Med 33:2339-2343

19. Gunnar WP, Merlotti GJ, Barrett J, Jonasson O 1986 Resuscitation from hemorrhagic shock. Alterations of the intracranial pressure after normal saline, 3\% saline and dextran-40. Ann Surg 204:686-692

20. Rose JC, Neill TA, Hemphill JC 2006 Continuous monitoring of the microcirculation in neurocritical care: an update on brain tissue oxygenation. Curr Opin Crit Care 12:97-102

21. Sahuquillo J, Amoros S, Santos A, Poca MA, Panzardo H, Dominguez L, Pedraza S 2000 Does an increase in cerebral perfusion pressure always mean a better oxygenated brain? A study in head-injured patients. Acta Neurochir Suppl 76:457-462

22. Stubbe HD, Greiner C, Westphal M, Rickert CH, Aken HV, Eichel V, Wassmann H, Daudel F, Hinder F 2006 Cerebral response to norepinephrine compared with fluid resuscitation in ovine traumatic brain injury and systemic inflammation. Crit Care Med 34:2651-2657

23. Mchedlishvili G 1986 Cerebral arterial behavior providing constant cerebral blood flow, pressure, and volume. In Bevan J (ed) Arterial Behavior and Blood Circulation in the Brain. Plenum Press, New York, pp 42-49

24. Holzschuh M, Woertgen C, Metz C, Brawanski A 1997 Dynamic changes of cerebral oxygenation measured by brain tissue oxygen pressure and near infrared spectroscopy. Neurol Res 19:246-248

25. Shonat RD, Wachman ES, Niu W, Koretsky AP, Farkas DL 1997 Near-simultaneous hemoglobin saturation and oxygen tension maps in mouse brain using an AOTF microscope. Biophys J 73:1223-1231

26. Delpy DT, Cope M, van der Zee P, Arridge S, Wray S, Wyatt J 1988 Estimation of optical pathlength through tissue from direct time of flight measurement. Phys Med Biol 33:1433-1442

27. Taylor GA, Short BL, Walker LK, Traystman RJ 1990 Intracranial blood flow: quantification with duplex Doppler and color Doppler flow US. Radiology 176: 231-236 